\title{
Prognostic significance of helicobacter pylori-infection in gastric diffuse large B-cell lymphoma
}

\author{
Yuan Cheng ${ }^{\dagger}$, Yinan Xiao, Ruofan Zhou, Yi Liao, Jing Zhou and Xuelei Ma ${ }^{* \dagger}$ (D)
}

\begin{abstract}
Background: Helicobacter pylori (H. pylori) is thought to have an oncogenic effect on the development of gastric malignancies. However, the effect of $\mathrm{H}$. pylori status on the prognosis of gastric diffuse large B-cell lymphoma $(\mathrm{DLBCL})$ remains unconfirmed. This study aimed to identify the prognostic importance of $H$. pylori infection in de novo gastric DLBCL.

Methods: One hundred and twenty-nine patients diagnosed with primary de novo gastric DLBCL at the West China Hospital of Sichuan University from 1st January 2009 to 31st May 2016 were included. The clinical features of the patients were documented. H. pylori status was assessed via urease breath tests and histologic examinations. The prognostic value of $\mathrm{H}$. pylori was verified via univariate and multivariate analyses.

Results: Over a median follow-up of 52.2 months (range 4-116), the 5-year overall survival (OS) for all patients was $78.7 \%$. Patients with $\mathrm{H}$. pylori infections had significantly better 5 -year PFS and OS than did the H. pylorinegative subgroup (5-year PFS, $89.3 \%$ vs. $74.1 \%, P=0.040 ; 5$-year OS, $89.7 \%$ vs. $71.8 \%, P=0.033$ ). Negative $H$. pylori status and poor ECOG performance were independent negative prognostic indicators for both PFS and OS (PFS, $P=0.045$ and $P=0.001$, respectively; OS, $P=0.021$ and $P<0.001$, respectively).

Conclusions: $H$. pylori status in de novo gastric DLBCL can be a promising predictor of disease outcome, and patients with negative $H$. pylori status require careful follow-up since they tend to have a worse outlook.
\end{abstract}

Keywords: Helicobacter pylori, Stomach, Diffuse large B-cell lymphoma, Prognosis, Survival analysis

\section{Background}

The gastrointestinal tract is a common site of extranodal non-Hodgkin lymphoma (NHL), with the stomach being the affected site in $60 \%$ of all NHL patients with digestive tract involvement [1, 2]. Among gastric lymphomas, mucosa-associated lymphoid tissue (MALT) lymphoma and diffuse large B-cell lymphoma (DLBCL) are the two most common types [3]. DLBCL in the stomach is a heterogeneous disease, and it is usually divided into two categories: DLBCL with features of MALT lymphoma (DLBCL (MALT)) and DLBCL without evidence of MALT (de novo DLBCL or pure DLBCL) [4]. Up to $20 \%$

\footnotetext{
* Correspondence: drmaxuelei@gmail.com

${ }^{\dagger}$ Yuan Cheng and Xuelei Ma contributed equally to this work.

State Key Laboratory of Biotherapy and Cancer Center, West China Hospital, Sichuan University and Collaborative Innovation Center, Chengdu, People's
} Republic of China

(c) The Author(s). 2019 Open Access This article is distributed under the terms of the Creative Commons Attribution 4.0 International License (http://creativecommons.org/licenses/by/4.0/), which permits unrestricted use, distribution, and reproduction in any medium, provided you give appropriate credit to the original author(s) and the source, provide a link to the Creative Commons license, and indicate if changes were made. The Creative Commons Public Domain Dedication waiver (http://creativecommons.org/publicdomain/zero/1.0/) applies to the data made available in this article, unless otherwise stated.

of patients with DLBCL have been identified as a concurrent component of MALT [5].

Helicobacter pylori (H. pylori), a spiral-shaped, microaerophilic bacterium that inhabits the human stomach, is estimated to colonize more than half of the world's human population [6]. The bacterium has been categorized as a class I carcinogen, giving rise to a new method for classifying gastric carcinoma [7]. Previous studies showed that $H$. pylori infections can induce a gastric lymphoid tissue response and that it might be an oncogenic factor during the development of malignant gastric lymphomas, including MALT lymphoma and DLBCL [8-10]. However, accumulating evidence has proven that H. pylori-positive status can support long-term survival and lead to better prognoses in gastric carcinoma patients [11-13]. It is thought that DLBCL (MALT) is independent of $H$. pylori status, as it fails to respond to 
antibiotic therapy according to the WHO (World Health Organization) classification and contains a component of high-grade transformed MALT lymphoma that differs from low-grade and $H$. pylori-dependent MALT lymphomas (MALT lymphoma) [5, 14-16]. However, numerous studies have found that a substantial percentage of gastric DLBCL (MALT) is associated with H. pylori infection and that it responds effectively to $H$. pylori eradication, especially early-stage DLBCL (MALT) [17, 18]. Of note, de novo DLBCL, the pathogenesis of which was once thought to be different from that of MALT lymphoma, has also been proven to correlate with $H$. pylori status based on limited data $[19,20]$. Until now, this clinically relevant finding has not been validated in large studies at other medical centers.

In this retrospective study, we evaluated the prognostic value of $H$. pylori status for patients with de novo DLBCL, especially among the early-stage population, at a larger medical center.

\section{Methods}

\section{Patients: diagnosis and treatment}

A retrospective review of all patients with the diagnosis of primary de novo DLBCL of the stomach at West China Hospital of Sichuan University from 1st January 2009 to 31st May 2016 was performed. Pathological specimens were obtained from both endoscopic biopsies and surgical resections, and diagnosis was based on the World Health Organization (WHO) classification system for hematologic malignancies [16]. Tumors without histological features of MALT lymphoma, including dense infiltration of centrocyte-like cells in the lamina propria and typical lymphoepithelial lesions [21, 22], were classified as de novo DLBCL. Only patients with primary involvement of stomach or with predominant gastric lesions were included. Patients with secondary gastric lymphoma or evidence of MALT origin were excluded. Paraffin-embedded, formalin-fixed tumor specimens where immunohistochemically stained for CD20, CD3, CD5, CD10, BCL6 and MUM1 (Fig. 1).

Patients were treated with the following therapeutic modalities singly or in combination: surgery, chemotherapy or radiotherapy. Chemotherapy referred to $\mathrm{CHOP}$ (cyclophosphamide, doxorubicin, vincristine and prednisone) or CHOP-like regimens, with or without rituximab (R).

\section{H. pylori infection}

The status of $H$. pylori infection was confirmed at the baseline for each case via the results of at least one of two tests: histologic examination or a ${ }^{14} \mathrm{C}$-urea breath test $\left({ }^{14} \mathrm{C}-\mathrm{UBT}\right)$. The histologic examination consisted of Warthin-Sharry (W-S) staining of tissue specimens. The results of the ${ }^{14} \mathrm{C}$-UBT were reported as ${ }^{14} \mathrm{C}$ disintegrations per minute $(\mathrm{dpm})$, and $\mathrm{dpm} \geq 100$ and $\mathrm{dpm}<100$ were interpreted as positive and negative, respectively. Of note, all $H$. pylori-positive patients received antibiotic therapy against $H$. pylori, including bismuth compounds, proton pump inhibitor (PPI) and two of the following antibiotics: clarithromycin, amoxicillin, metronidazole or tetracycline.

\section{Clinical evaluation}

Staging workups included the collection of a detailed medical history, a physical examination that included examination of the peripheral lymph nodes and Waldeyer's ring, complete hematological biochemical examinations, including serum lactate dehydrogenase (LDH), computed tomography $(\mathrm{CT})$, gastric endoscopy, endoscopic ultrasonography, positron emission tomography (PET)/CT, and bone marrow aspiration and biopsy. For patients who received surgical interventions, the intraoperative exploration and pathological results were further considered. The staging and classification of the lesions were based on the Lugano staging system [23]. Furthermore, the performance status of each patient was assessed according to the Eastern Cooperative Oncology Group (ECOG) scale and the International Prognostic Index (IPI).

\section{Statistical analyses}

Pearson's chi-squared test and Fisher's exact test were used to evaluate the relationships between $H$. pylori status and other prognostic indicators and clinicopathological characteristics. Analyses were performed using follow-up data available on 31st May 2018. The primary endpoints of the current study were progression-free survival (PFS) and overall survival (OS). PFS was defined as the date of initial diagnosis until disease progression, relapse or death due to any cause. OS was measured from the date of diagnosis to the date of death from any cause or the date of a survivor's final follow-up. Survival curves were estimated via the Kaplan-Meier method, and the differences between survival curves were compared via the log-rank test. All of the significant variables in the univariate analyses were included in multivariate analyses to evaluate the independent risk factors for PFS and OS via the Cox proportional hazards regression model. SPSS version 21.0 was used for the data analyses. $P$-values less than 0.05 were considered statistically significant. Our team has reviewed the data and reached an agreement on this final version.

\section{Results}

Baseline characteristics

The demographic baseline data and clinicopathologic parameters of the 129 included patients with de novo gastric DLBCL are listed in Table 1 . The median age was 55 years old with a range of $21-84.66(51.2 \%)$ of the patients were women. Among the 129 patients, 64 


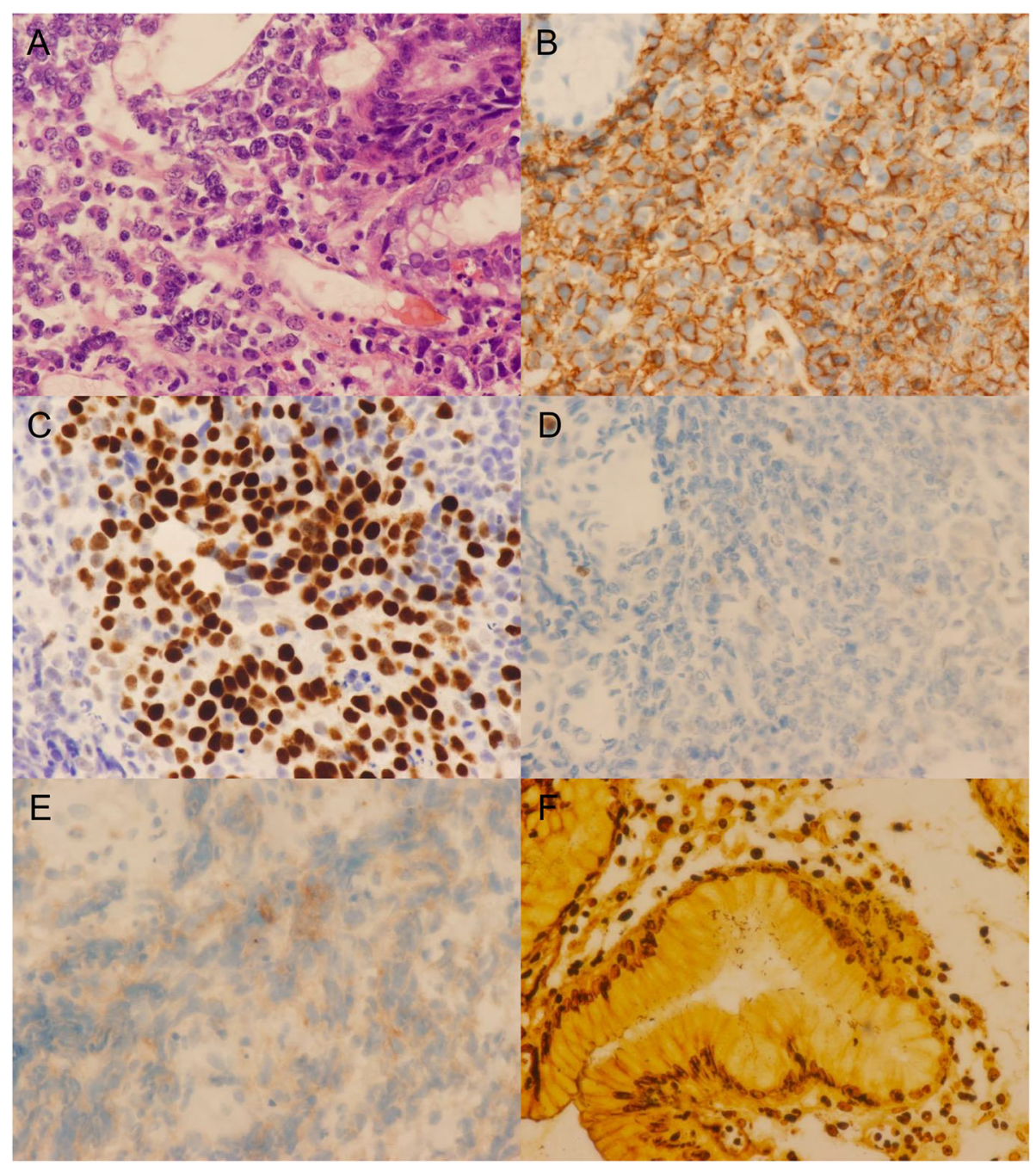

Fig. 1 An example of immunohistochemical features of germinal center B-cell de novo gastric DLBCL. a diffuse large cells infiltrating the mucosa (hematoxylin-eosin (H\&E) staining, $\times 400)$, (b) positive CD20 expression, (c) positive BCL6 expression, (d) negative expression of CD10, (e) negative expression of MUM1, and (f) Warthin-Starry staining of H. pylori

(49.6\%) were negative for $H$. pylori and 65 (50.4\%) were positive for H. pylori. $71(86.6 \%)$ patients had lesions in the antrum or corpus of the stomach, and B symptoms appeared in $45(34.9 \%)$ patients. Most patients (> 50\%) were early-stage and had better performance based on Lugano stage, IPI score and ECOG scale. Of note, the distribution of Lugano stage, IPI risk group, resection surgical treatment and LDH level were significantly associated with the $H$. pylori-positive and -negative subgroups $(P<0.05)$. Patients with $H$. pylori infections tended to remain in an early-stage of de novo DLBCL, whereas patients in the $H$. pylori-negative subgroup had relatively poor performance. The remaining clinical variables were similar in both $H$. pylori subgroups $(P>0.05)$.

Over a median follow-up of 52.2 months (range 4$116)$, the 5 -year OS for all patients was $78.7 \%$. The overall median PFS was 91.8 months $(95 \%$ confidence interval [CI] 83.8-99.7), and the median overall survival (OS) was 96.0 months (95\% CI 88.9-103.0). Patients with H. pylori-positive de novo gastric DLBCL had significantly better 5-year PFS and OS than patients in the H. pylorinegative subgroup (5-year PFS, $89.3 \%$ vs. $74.1 \%, P=0.040$; 5 -year OS, $89.7 \%$ vs. $71.8 \%, P=0.033$ ) (Tables 2 and 3 ).

\section{Univariate and multivariate analyses}

We next investigated the associations between important clinicopathologic parameters and patient survival via a Cox proportional hazard regression analysis (Tables 2 and 3 ).

Upon follow-up, 28 patients showed disease progression (22 were $H$. pylori-negative and 6 were $H$. pyloripositive). The mean PFS was 100.6 months (95\% CI 92.0-109.2) in patients positive for H. pylori, compared with 85.0 months (95\% CI 74.2-95.7) for patients in the 
Table 1 Association between clinicopathologic features and H. pylori status of 129 patients with de novo gastric diffuse large B-cell lymphoma

\begin{tabular}{|c|c|c|c|c|}
\hline Patients & Number of patients $n=129(\%)$ & H. pylori-negative $n=64(\%)$ & H. pylori-positive $n=65(\%)$ & $p$ \\
\hline \multicolumn{5}{|l|}{ Gender } \\
\hline Female & $66(51.2)$ & $39(53.4)$ & $27(48.2)$ & \multirow[t]{2}{*}{0.557} \\
\hline Male & 63(48.8) & $34(46.6)$ & 29(51.8) & \\
\hline \multicolumn{5}{|c|}{ Age, years } \\
\hline$<60$ & 73(56.6) & 43(58.9) & $30(53.6)$ & \multirow[t]{2}{*}{0.545} \\
\hline$\geq 60$ & $56(43.4)$ & $30(41.1)$ & $26(46.4)$ & \\
\hline \multicolumn{5}{|c|}{ Presence of B symptoms } \\
\hline No & $84(65.1)$ & 43(58.9) & $41(73.2)$ & \multirow[t]{2}{*}{0.091} \\
\hline Yes & 45(34.9) & $30(41.1)$ & 15(26.8) & \\
\hline \multicolumn{5}{|c|}{ Tumor sites } \\
\hline Proximal & $11(13.4)$ & $7(17.1)$ & $4(9.8)$ & \multirow[t]{2}{*}{0.331} \\
\hline Distal & $71(86.6)$ & $34(82.9)$ & $37(90.2)$ & \\
\hline \multicolumn{5}{|c|}{ Lugano stage } \\
\hline$|/| \mid$ & $88(66.7)$ & $44(60.3)$ & 44(78.6) & \multirow[t]{2}{*}{0.027} \\
\hline \|E/IV & $41(33.3)$ & 29(39.7) & 12(21.4) & \\
\hline \multicolumn{5}{|c|}{$\mathrm{IPI}$ risk group } \\
\hline Low (intermediate) risk & 109(84.5) & $57(78.1)$ & $52(92.9)$ & \multirow[t]{2}{*}{0.022} \\
\hline High (intermediate) risk & $20(15.5)$ & 16(21.9) & $4(7.1)$ & \\
\hline \multicolumn{5}{|c|}{ ECOG } \\
\hline $0-1$ & 117(90.7) & $65(89.0)$ & $52(92.9)$ & \multirow[t]{2}{*}{0.460} \\
\hline$\geq 2$ & $12(9.3)$ & $8(11.0)$ & $4(7.1)$ & \\
\hline \multicolumn{5}{|c|}{ Surgical treatment } \\
\hline No & $87(67.4)$ & 43(58.9) & 44(78.6) & \multirow[t]{2}{*}{0.018} \\
\hline Yes & $42(32.6)$ & $30(41.1)$ & $12(21.4)$ & \\
\hline \multicolumn{5}{|c|}{ Histological analyses } \\
\hline non-GCB & $56(70.0)$ & $28(66.7)$ & 28(73.7) & \multirow[t]{2}{*}{0.494} \\
\hline GCB & $24(30.0)$ & 14(33.3) & $10(26.3)$ & \\
\hline & & $\mathrm{LDH}$ & & \\
\hline$<220 \mathrm{U} / \mathrm{L}$ & 92(71.3) & $44(60.3)$ & 48(85.7) & \multirow[t]{2}{*}{0.002} \\
\hline$\geq 220 \mathrm{U} / \mathrm{L}$ & $37(28.7)$ & 29(39.7) & $8(14.3)$ & \\
\hline
\end{tabular}

The $P$-values with statistical significance are shown in bold

H. pylori-negative subgroup $(P=0.040)$. The presence of B symptoms $(P=0.012)$, advanced Lugano stage $(P=$ $0.013)$, poor ECOG performance status $(P<0.001)$, classification into higher IPI risk groups $(P<0.001)$, lack of resection surgery $(P=0.044)$ and negative $H$. pylori status $(P=0.040)$ were significantly associated with poor PFS of de novo gastric DLBCL in the univariate analyses
(Table 2). The multivariate analyses revealed that the presence of B symptoms (hazard ratio $=2.605 ; P=0.004$ ) and poor ECOG performance status (hazard ratio $=$ 5.002; $P=0.001$ ) could independently predict poor PFS outcomes of de novo gastric DLBCL. However, positive H. pylori status was a positive predictor of PFS (hazard ratio $=0.379 ; P=0.045)$ (Table 2 ). 
Table 2 Univariate and multivariate analysis of prognostic factors for progression-free survival in 129 patients with de novo gastric diffuse large B-cell lymphoma

\begin{tabular}{|c|c|c|c|c|c|c|c|c|c|}
\hline \multirow[t]{2}{*}{ Patients } & \multirow{2}{*}{$\begin{array}{l}\text { Number } \\
\text { of } \\
\text { patients } \\
n=129\end{array}$} & \multirow{2}{*}{$\begin{array}{l}\text { Number } \\
\text { of event } \\
n=28\end{array}$} & \multirow{2}{*}{$\begin{array}{l}\text { Median } \\
\text { PFS }\end{array}$} & \multirow[t]{2}{*}{$95 \% \mathrm{Cl}$} & \multirow{2}{*}{$\begin{array}{l}\text { Actuarial } \\
5 \text {-year } \\
\text { progression-free } \\
\text { survival (\%) }\end{array}$} & \multicolumn{2}{|c|}{ Univariate analysis } & \multicolumn{2}{|c|}{ Multivariate analysis } \\
\hline & & & & & & $\mathrm{HR}(95 \% \mathrm{Cl})$ & $p$ & $\mathrm{HR}(95 \% \mathrm{Cl})$ & $p$ \\
\hline \multicolumn{10}{|l|}{ Gender } \\
\hline Female & 66 & 15 & 79.2 & $70.1-88.3$ & 78.0 & 1 & 0.691 & - & \\
\hline Male & 63 & 13 & 94.0 & $83.4-104.6$ & 81.8 & \multicolumn{2}{|c|}{ 0.860(0.409-1.809) } & - & \\
\hline \multicolumn{10}{|c|}{ Age, years } \\
\hline$<60$ & 73 & 12 & 96.4 & 86.9-105.9 & 87.7 & 1 & 0.098 & 1 & 0.871 \\
\hline$\geq 60$ & 56 & 16 & 85.6 & $73.1-98.1$ & 70.1 & \multicolumn{2}{|c|}{$1.886(0.889-4.003)$} & \multicolumn{2}{|c|}{$1.078(0.435-2.671)$} \\
\hline \multicolumn{10}{|c|}{ Presence of B symptoms } \\
\hline No & 84 & 13 & 99.5 & $91.3-107.6$ & 86.5 & 1 & 0.012 & 1 & 0.004 \\
\hline Yes & 45 & 15 & 66.3 & $54.8-77.7$ & 68.1 & $2.605(1.235-5$ & .493) & $3.337(1.466-7$ & .595) \\
\hline \multicolumn{10}{|c|}{ Tumor sites } \\
\hline Proximal & 11 & 4 & 55.0 & $34.8-75.2$ & 49.1 & 1 & 0.213 & - & \\
\hline Distal & 71 & 16 & 91.1 & $80.5-101.8$ & 78.9 & 0.495(0.164-1 & .495) & - & \\
\hline \multicolumn{10}{|c|}{ Lugano stage } \\
\hline$|/| \mid$ & 88 & 14 & 98.2 & $89.6-106.8$ & 85.1 & 1 & 0.013 & 1 & 0.666 \\
\hline IIE/IV & 41 & 14 & 66.4 & $53.4-79.3$ & 69.1 & $2.573(1.222-5$ & .417) & $1.129(0.651-$ & $960)$ \\
\hline \multicolumn{10}{|c|}{$\mathrm{IPI}$ risk group } \\
\hline Low (intermediate) risk & 109 & 17 & 102.1 & $95.3-108.9$ & 85.3 & 1 & $<0.001$ & 1 & 0.117 \\
\hline High (intermediate) risk & 20 & 11 & 58.5 & $39.4-77.6$ & 50.0 & 4.364(2.033-9 & .366) & $2.924(0.764-$ & 1.186) \\
\hline \multicolumn{10}{|c|}{ ECOG } \\
\hline $0-1$ & 117 & 19 & 97.8 & $90.3-105.4$ & 85.3 & 1 & $<0.001$ & 1 & 0.001 \\
\hline$\geq 2$ & 12 & 9 & 30.7 & $12.0-49.3$ & 27.8 & $8.190(3.644-1$ & 8.407) & $5.002(1.970-$ & 2.698) \\
\hline \multicolumn{10}{|c|}{ Surgical treatment } \\
\hline No & 87 & 22 & 68.1 & $61.0-75.2$ & 76.0 & 1 & 0.044 & 1 & 0.068 \\
\hline Yes & 42 & 6 & 102.0 & $91.7-112.4$ & 87.6 & $0.384(0.152-c$ & 1974) & $0.381(0.135-$ & .075) \\
\hline \multicolumn{10}{|c|}{ Histological analyses } \\
\hline non-GCB & 56 & 11 & 77.0 & $67.9-86.1$ & 85.6 & 1 & 0.702 & - & \\
\hline GCB & 24 & 6 & 76.6 & $62.8-90.5$ & 70.5 & $1.214(0.448-3$ & .290) & - & \\
\hline \multicolumn{10}{|c|}{ Lactate dehydrogenase } \\
\hline$<220 \mathrm{U} / \mathrm{L}$ & 92 & 16 & 96.6 & $87.9-105.3$ & 82.9 & 1 & 0.059 & 1 & 0.646 \\
\hline$\geq 220 \mathrm{U} / \mathrm{L}$ & 37 & 12 & 69.8 & $56.7-82.9$ & 72.8 & $2.059(0.973-4$ & 357) & $1.108(0.716-$ & .713) \\
\hline \multicolumn{10}{|c|}{ H. pylori status } \\
\hline Negative & 73 & 22 & 85.0 & 74.2-95.7 & 74.1 & 1 & 0.040 & 1 & 0.045 \\
\hline Positive & 56 & 6 & 100.6 & $92.0-109.2$ & 89.3 & $0.388(0.157-0$ & .959) & $0.379(0.147-C$ & .978) \\
\hline
\end{tabular}

The $P$-values with statistical significance are shown in bold 
Table 3 Univariate and multivariate analysis of prognostic factors for overall survival in 129 patients with de novo gastric diffuse large B-cell lymphoma

\begin{tabular}{|c|c|c|c|c|c|c|c|c|c|}
\hline \multirow[t]{2}{*}{ Patients } & \multirow{2}{*}{$\begin{array}{l}\text { Number } \\
\text { of } \\
\text { patients } \\
n=129\end{array}$} & \multirow{2}{*}{$\begin{array}{l}\text { Number } \\
\text { of death } \\
n=25\end{array}$} & \multirow{2}{*}{$\begin{array}{l}\text { Median } \\
\text { OS }\end{array}$} & \multirow[t]{2}{*}{$95 \% \mathrm{Cl}$} & \multirow{2}{*}{$\begin{array}{l}\text { Actuarial } \\
5 \text {-year } \\
\text { overall } \\
\text { survival } \\
(\%)\end{array}$} & \multicolumn{2}{|c|}{ Univariate analysis } & \multicolumn{2}{|c|}{ Multivariate analysis } \\
\hline & & & & & & $\mathrm{HR}(95 \% \mathrm{Cl})$ & $p$ & HR (95\% Cl) & $p$ \\
\hline \multicolumn{10}{|l|}{ Gender } \\
\hline Female & 63 & 14 & 81.7 & $73.3-90.2$ & 76.9 & 1 & 0.522 & - & \\
\hline Male & 66 & 11 & 98.5 & $89.1-107.8$ & 80.3 & \multicolumn{2}{|c|}{$0.773(0.351-1.702)$} & \multicolumn{2}{|l|}{-} \\
\hline \multicolumn{10}{|c|}{ Age, years } \\
\hline$<60$ & 73 & 9 & 102.2 & $94.4-110.0$ & 85.6 & 1 & 0.033 & 1 & 0.525 \\
\hline$\geq 60$ & 56 & 16 & 86.8 & 74.9-98.8 & 69.9 & \multicolumn{2}{|c|}{$2.434(1.075-5.511)$} & \multicolumn{2}{|c|}{$1.384(0.507-3.779)$} \\
\hline \multicolumn{10}{|c|}{ Presence of B symptoms } \\
\hline No & 84 & 13 & 99.9 & $91.9-107.9$ & 84 & 1 & 0.139 & 1 & 0.094 \\
\hline Yes & 45 & 12 & 76.3 & $65.8-86.8$ & 68.9 & $1.810(0.825-3$ & 969) & $2.129(0.879-5$ & 154) \\
\hline \multicolumn{10}{|c|}{ Tumor sites } \\
\hline Proximal & 11 & 4 & 60.2 & $44.4-75.9$ & 60.6 & 1 & 0.212 & - & \\
\hline Distal & 71 & 14 & 95.6 & $86.1-105.1$ & 76.4 & 0.492 & & - & \\
\hline \multicolumn{10}{|c|}{ Lugano stage } \\
\hline |//I & 88 & 12 & 102.1 & $94.9-109.4$ & 85.3 & 1 & 0.012 & 1 & 0.667 \\
\hline IIE/IV & 41 & 13 & 70.3 & $57.7-82.7$ & 66.6 & $2.756(1.251-6$ & 070) & $1.292(0.402-4$ & 153) \\
\hline \multicolumn{10}{|c|}{ IPI risk group } \\
\hline Low (intermediate) risk & 109 & 15 & 102.0 & $95.4-108.5$ & 83.7 & 1 & $<0.001$ & 1 & 0.256 \\
\hline High (intermediate) risk & 20 & 10 & 55.1 & $37.2-72.9$ & 51.4 & $5.088(2.263-1$ & $.442)$ & $2.242(0.556-\varsigma$ & 035) \\
\hline \multicolumn{10}{|c|}{ ECOG } \\
\hline $0-1$ & 117 & 16 & 102.1 & $95.8-108.4$ & 83.7 & 1 & $<0.001$ & 1 & $<0.001$ \\
\hline$\geq 2$ & 12 & 9 & 33.3 & $16.6-50.1$ & 31.3 & $9.741(4.249-2$ & $336)$ & $6.216(2.391-1$ & $5.159)$ \\
\hline \multicolumn{10}{|c|}{ Surgical treatment } \\
\hline No & 87 & 21 & 69.9 & $63.2-76.6$ & 73.7 & 1 & 0.021 & 1 & 0.030 \\
\hline Yes & 42 & 4 & 107.9 & $100.4-115.5$ & 89.4 & $0.281(0.095-0$ & 327) & $0.273(0.084-c$ & 881) \\
\hline \multicolumn{10}{|c|}{ Histological analyses } \\
\hline non-GCB & 56 & 10 & 80.4 & $72.3-88.6$ & 78.5 & 1 & 0.873 & - & \\
\hline GCB & 24 & 5 & 80.9 & $68.3-93.5$ & 76.9 & $0.957(0.559-1$ & 537) & - & \\
\hline \multicolumn{10}{|c|}{ Lactate dehydrogenase } \\
\hline$<220 \mathrm{U} / \mathrm{L}$ & 92 & 15 & 99.1 & $91.3-106.9$ & 81.7 & 1 & 0.134 & 1 & 0.885 \\
\hline$\geq 220 \mathrm{U} / \mathrm{L}$ & 37 & 10 & 75.4 & $63.4-87.3$ & 71.5 & $1.845(0.828-4$ & 108) & $1.065(0.451-2$ & 517) \\
\hline \multicolumn{10}{|c|}{ H. pylori status } \\
\hline Negative & 73 & 20 & 89.3 & $79.4-99.3$ & 71.8 & 1 & 0.033 & 1 & 0.021 \\
\hline Positive & 56 & 5 & 102.7 & $94.9-110.5$ & 89.7 & $0.344(0.129-0$ & 917) & $0.292(0.103-C$ & 828) \\
\hline
\end{tabular}



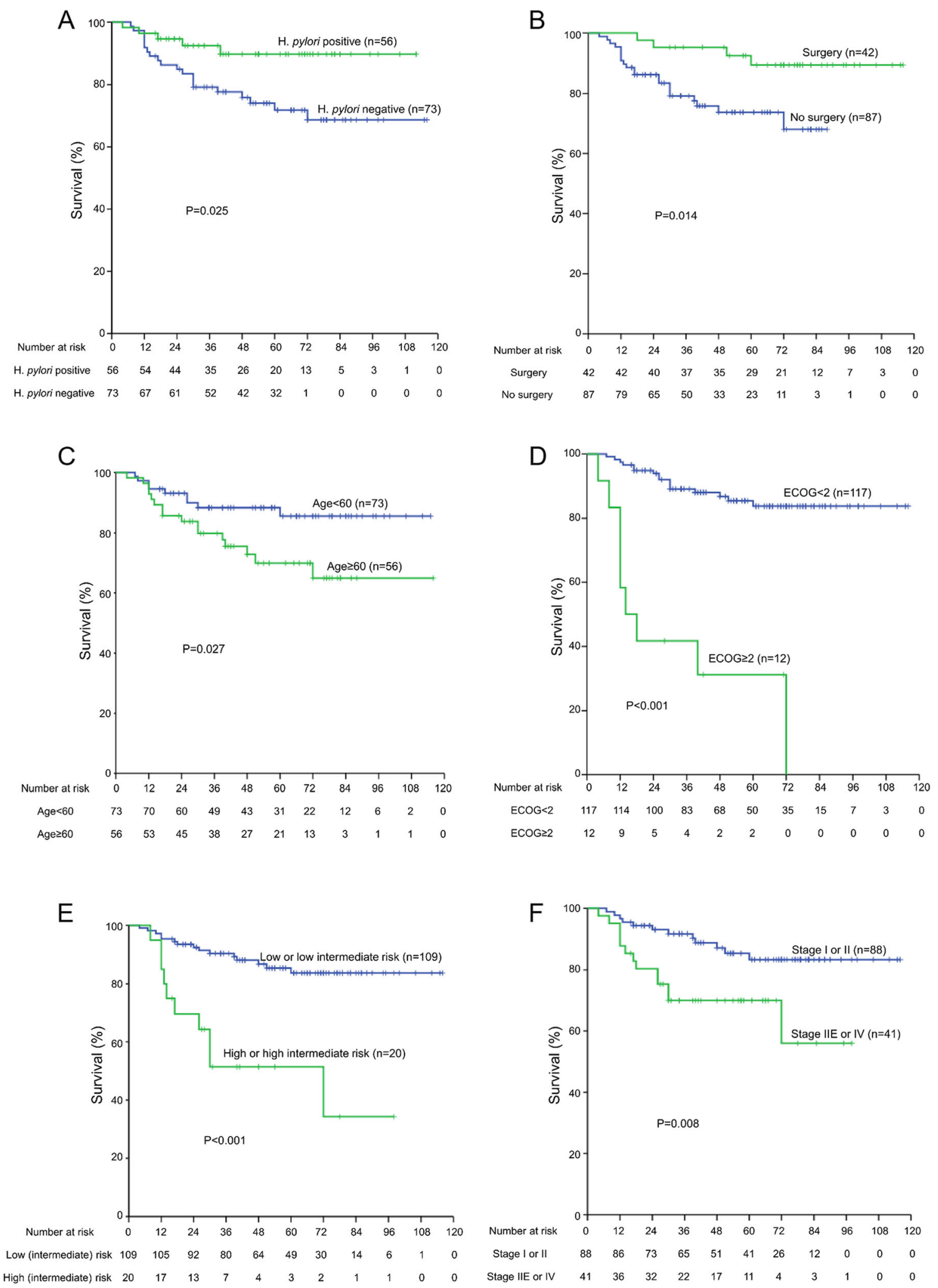

Fig. 2 (See legend on next page.) 
(See figure on previous page.)

Fig. 2 Effects of H. pylori status, surgery, age, ECOG performance, IPI risk group, and Lugano stage on overall survival of patients with de novo gastric diffuse large B-cell lymphoma according to Kaplan-Meier analysis. a Positive H. pylori status $(p=0.025)$, (b) Surgery $(p=0.014)$, (c) Age $<60$ ( $p=0.027)$, (d) ECOG $<2(p<0.001)$, (e) low and low intermediate risk $(p<0.001)$ and $(\mathbf{f})$ Lugano stage I and II $(p=0.008)$ are positive prognostic factors for de novo gastric DLBCL

Among the 25 patients who died during the follow-up, 5 were $H$. pylori-positive and the remained were $H$. pylorinegative. The mean OS was 102.7 months (95\% CI 94.9-110.5) in H. pylori-positive patients, compared with 89.3 months (95\% CI 79.4-99.3) in the patients in the $H$. pylori-negative subgroup $(P=0.033)$. Univariate analyses showed significant associations between OS and age $(\mathrm{P}=0.033)$, Lugano staging $(P=0.012)$, ECOG performance $(P<0.001)$, IPI risk group $(\mathrm{P}<$ $0.001)$, resection surgery $(P=0.021)$, and $H$. pylori infection $(P=0.020)$ (Table 3$)$. Multivariate analyses revealed that ECOG performance (hazard ratio $=$ 6.216; $P<0.001)$ was an independent prognostic index for poor OS in de novo gastric DLBCL. Resection surgery (hazard ratio $=0.273 ; P=0.003$ ) and $H$. pylori infection (hazard ratio $=0.292 ; \mathrm{P}=0.021$ ) were positive prognostic factors for OS (Table 3).

\section{Kaplan-Meier survival analysis}

Kaplan-Meier survival curves showed that $H$. pylori infection status $(P=0.025)$, resection surgery $(P=0.014)$, age $(P=0.027)$, ECOG performance status $(P<0.001)$, IPI risk group $(\mathrm{P}<0.001)$ and Lugano stage $(P=0.008)$ were significantly associated with OS of de novo DLBCL (Fig. 2).

\section{Subgroup analysis}

Of note, in stage-specific analyses, $H$. pylori infection presented a significant association with OS in stage I or II $(P=0.034)$ but not in stage IIE or IV $(P=0.675)$ (Fig. 3$)$.

\section{Discussion}

Gastric MALT lymphoma has been claimed to be strongly associated with $H$. pylori infection, and eradication of $H$. pylori (HPE) even without oncological treatment has been used as the first-line treatment for this disease, especially for early stage MALT lymphoma [24, 25]. Gastric DLBCL (MALT) results from high-grade transformation of MALT lymphoma and is independent of $H$. pylori infection; however, previous studies have also proven that $H$. pylori eradication can lead to complete remission in a certain fraction of patients with $H$. pylori-positive DLBCL (MALT) [26]. Researchers have also found that some de novo DLBCL patients also presented complete remission after $H$. pylori eradication [27, 28]. Furthermore, an association between $H$. pylori infection and de novo DLBCL was validated in a large cohort [29]. Our results suggested that $H$. pylori-positive status was strongly indicative of better gastric de novo DLBCL prognosis.
H. pylori-induced lymphomagenesis is a multistep process involving $H$. pylori virulence factors (e.g., CagA, VacA and OipA), host factors and environmental conditions. Cytotoxin-associated gene A (CagA) protein, which is exposed on the surface of $H$. pylori cells via a type IV secretion system, is the most extensively studied $H$. pylori virulence factor. CagA can directly pass through the host membrane via an interaction with phosphatidylserine, after which it perturbs cell signaling in a way that can lead to oncogenesis [30]. Consistent with previous studies, our results indicated that despite the carcinogenic effect of $H$. pylori, $H$. pylori infection was associated with a less aggressive subtype of de novo DLBCL, and these patients showed better prognoses $[19,20]$. Further subgroup analyses suggested that $H$. pylori infection was significantly associated with better survival outcomes in patients with early-stage gastric de novo DLBCL. As the identification of $H$. pylori status is possible during early cancer stages, it is useful for stratifying patients into risk groups and for predicting adverse disease outcomes; thus, its identification of as an independent predictor could establish it as a promising tool in clinical practice for helping to make treatment decisions.

One possible explanation for the critical role of H. pylori infection in improving the outlook of gastric de novo DLBCL is the immune cross-reactivity between $H$. pylori and the malignant B-cells of gastric DLBCL. Furthermore, previous studies have hypothesized that antigenic mimicry between $H$. pylori and the gastric mucosa might result in immune cross-reactions that affect tumor cells and suppress tumor progression as well as metastasis in gastric carcinoma [31, 32]. Furthermore, the immune response induced by $H$. pylori might also be cross-reactive against the malignant B-cells of gastric DLBCL since H. pylori can transfer CagA into both epithelial cells and B-lymphocytes and promote CagA expression in malignant B-cells [33]. Immune cross-reactions with malignant cells are characterized by the presence of mimic or absorbed H. pylori antigens, which results in improved survival outcomes in $H$. pylori-positive gastric DLBCL.

These newly uncovered underlying mechanisms demonstrate that $H$. pylori-positive de novo gastric DLBCL has less aggressive behavior. By examining genome-wide expression profiles of both mRNAs and miRNAs in $H$. pylori-positive and -negative de novo gastric DLBCL tissue specimens, a previous study confirmed that $H$. pylori infection is associated with a higher level of miR-200, which can inhibit Zinc-finger E-box-binding homeobox 1 (ZEB1) [20]. ZEB1 is expressed at a significantly higher 


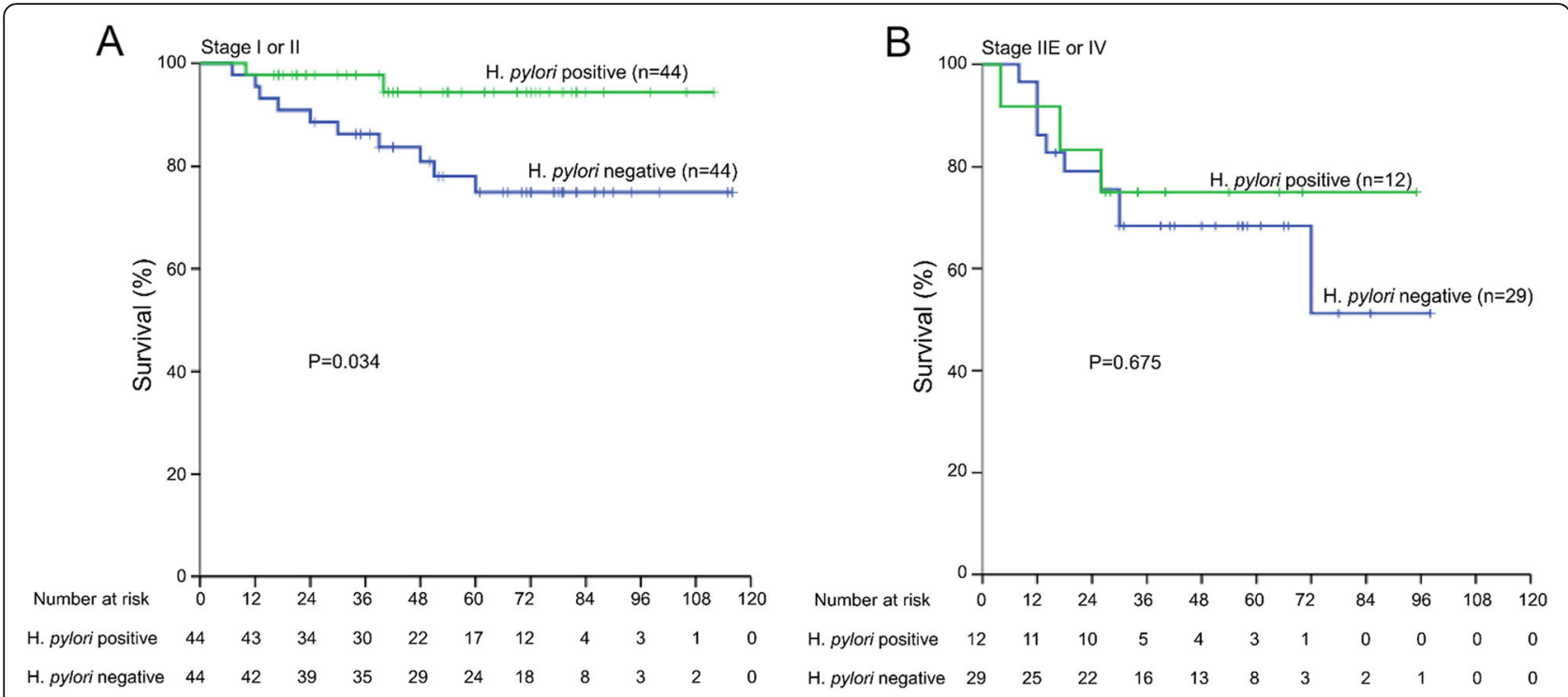

Fig. 3 Effects of $H$. pylori status according to Lugano stage on overall survival of patients with de novo gastric diffuse large B-cell lymphoma. Positive H. pylori status is associated with better prognosis in patients of (a) Lugano stage I and II rather than those of (b) stage IIE and IV ( $p=$ 0.034 and $p=0.675$, respectively)

level in DLBCL than that in reactive lymphoid tissue and is linked to an adverse prognosis in DLBCL [34]. ZEB1 promotes DLBCL progression via downregulation of BCL6, which is a known positive predictor for DLBCL [20]. However, the specific role of BCL6 in DLBCL progression requires further investigation. In light of its role in carcinogenesis, $H$. pylori might also affect other biological behaviors of gastric DLBCL, which may contribute to the survival benefits observed in the H. pyloripositive subgroup. Inherent differences in the tumors that develop secondary to $H$. pylori-infection and the carcinogenic functions of $H$. pylori infection require additional study.

This study is limited by its retrospective nature and single-institution bias. Furthermore, not all patients included in this study were treated with rigorous standard therapy. Some of the patients received chemotherapy without rituximab due to economic pressure, while other patients underwent surgery because they were either diagnosed with gastric DLBCL after surgery, or they were diagnosed years ago when surgery was still commonly performed. Despite the aforementioned limitations, to our knowledge, this study is the largest report examining the prognostic role of $H$. pylori in de novo gastric DLBCL.

\section{Conclusions}

In summary, patients with primary gastric de novo DLBCL without $H$. pylori infection are more likely to have poor prognoses than patients with the infection; therefore, the patients without $H$. pylori may benefit from more aggressive treatment and more systematic follow-up.

\section{Abbreviations}

CagA: Cytotoxin-associated gene A; CEA: Carcinoembryonic antigen; DLBCL: Diffuse large B-cell lymphoma; ECOG: Eastern Cooperative Oncology Group; EFS: Progression-free survival; GCB: Germinal center B-cell; H. pylori: Helicobacter pylori; IPI: International Prognostic Index; LDH: Lactate dehydrogenase; MALT: Mucosa-associated lymphoid tissue; NHL: NonHodgkin's Lymphomas; OS: Overall survival

\section{Acknowledgements}

Not applicable.

\section{Authors' contributions}

Study concept and design: XLM; Acquisition of data: YC, JZ and YL; Analysis and interpretation of data: $Y C$ and $X L M$; Drafting of the manuscript: $Y C$ and YNX; Critical revision of the manuscript for important intellectual content: RF Z, YNX, and XLM; Statistical analysis: YC, YL and JZ; Study supervision: XLM. All authors read and approved the final manuscript.

Funding

Not applicable.

\section{Availability of data and materials}

All data generated or analysed during this study are included in this published article.

\section{Ethics approval and consent to participate}

Approval for this retrospective research was obtained from the institutional review board of West China hospital, Sichuan University. Written informed consent was obtained from all included patients.

Consent for publication

Not applicable.

Competing interests

The authors declare that they have no competing interests. 
Received: 21 March 2019 Accepted: 20 August 2019

Published online: 28 August 2019

\section{References}

1. Sabattini E, Bacci F, Sagramoso C, et al. WHO classification of tumours of haematopoietic and lymphoid tissues in 2008: an overview. Pathologica. 2010;102:83-7.

2. Tondini C, Giardini R, Bozzetti F, et al. Combined modality treatment for primary gastrointestinal non-Hodgkin's lymphoma: the Milan Cancer institute experience. Ann Oncol. 1993;4:831-7.

3. Howell JM, Auer-Grzesiak I, Zhang J, et al. Increasing incidence rates, distribution and histological characteristics of primary gastrointestinal nonHodgkin lymphoma in a North American population. Can J Gastroenterol. 2012;26:452-6.

4. Jaffe ES, Harris NL, Stein $\mathrm{H}$, et al. Classification of lymphoid neoplasms: the microscope as a tool for disease discovery. Blood. 2008;112:4384-99.

5. Psyrri A, Papageorgiou S, Economopoulos T. Primary extranodal lymphomas of stomach: clinical presentation, diagnostic pitfalls and management. Ann Oncol. 2008;19:1992-9.

6. Hatakeyama M. Oncogenic mechanisms of the helicobacter pylori CagA protein. Nat Rev Cancer. 2004;4:688-94.

7. Schistosomes, liver flukes and Helicobacter pylori. IARC Working Group on the Evaluation of Carcinogenic Risks to Humans. Lyon, 7-14 June 1994. IARC Monogr Eval Carcinog Risks Hum. 1994;61:1-241.

8. Wotherspoon AC, Ortiz-Hidalgo C, Falzon MR, et al. Helicobacter pyloriassociated gastritis and primary B-cell gastric lymphoma. Lancet. 1991; 338:1175-6.

9. Amieva M, Peek RM. Pathobiology of helicobacter pylori-induced gastric Cancer. Gastroenterology. 2016;150:64-78.

10. Suzuki T, Matsuo K, Ito H, et al. A past history of gastric ulcers and helicobacter pylori infection increase the risk of gastric malignant lymphoma. Carcinogenesis. 2006;27:1391-7.

11. Meimarakis G, Winter H, Assmann I, et al. Helicobacter pylori as a prognostic indicator after curative resection of gastric carcinoma: a prospective study. Lancet Oncol. 2006;7:211-22

12. Marrelli D, Pedrazzani C, Berardi A, et al. Negative helicobacter pylori status is associated with poor prognosis in patients with gastric cancer. Cancer 2009;115:2071-80.

13. Postlewait LM, Squires MH, Kooby DA, et al. Preoperative helicobacter pylori infection is associated with increased survival after resection of gastric adenocarcinoma. Ann Surg Oncol. 2016;23:1225-33.

14. Hussell T, Isaacson PG, Crabtree JE, et al. The response of cells from lowgrade B-cell gastric lymphomas of mucosa-associated lymphoid tissue to helicobacter pylori. Lancet. 1993;342:571-4.

15. Neubauer A, Thiede C, Morgner A, et al. Cure of helicobacter pylori infection and duration of remission of low-grade gastric mucosa-associated lymphoid tissue lymphoma. J Natl Cancer Inst. 1997;89:1350-5.

16. Swerdlow SH, Campo E, Harris NL, et al. WHO classification of tumors of hematopoietic and lymphoid tissues. 4th ed. Lyon: IARC Press; 2008

17. Chen LT, Lin JT, Shyu RY, et al. Prospective study of helicobacter pylori eradication therapy in stage $\mathrm{I}(\mathrm{E})$ high-grade mucosa-associated lymphoid tissue lymphoma of the stomach. J Clin Oncol. 2001;19:4245-51.

18. Morgner A, Miehlke S, Fischbach W, et al. Complete remission of primary high-grade B-cell gastric lymphoma after cure of helicobacter pylori infection. J Clin Oncol. 2001;19:2041-8.

19. Kuo SH, Yeh KH, Chen LT, et al. Helicobacter pylori-related diffuse large Bcell lymphoma of the stomach: a distinct entity with lower aggressiveness and higher chemosensitivity. Blood Cancer J. 2014;4:e220.

20. Huang WT, Kuo SH, Cheng AL, et al. Inhibition of ZEB1 by miR-200 characterizes helicobacter pylori-positive gastric diffuse large B-cell lymphoma with a less aggressive behavior. Mod Pathol. 2014;27:1116-25.

21. Chan JK, Ng CS, Isaacson PG. Relationship between high-grade lymphoma and low-grade B-cell mucosa-associated lymphoid tissue lymphoma (MALToma) of the stomach. Am J Pathol. 1990;136:1153-64.

22. de Jong $\mathrm{D}$, Boot $\mathrm{H}$, van Heerde $\mathrm{P}$, et al. Histological grading in gastric lymphoma: pretreatment criteria and clinical relevance. Gastroenterology. 1997:112:1466-74.

23. Rohatiner A, d'Amore F, Coiffier B, et al. Report on a workshop convened to discuss the pathological and staging classifications of gastrointestinal tract lymphoma. Ann Oncol. 1994;5:397-400.
24. Nakamura S, Sugiyama T, Matsumoto T, et al. Long-term clinical outcome of gastric MALT lymphoma after eradication of helicobacter pylori: a multicentre cohort follow-up study of 420 patients in Japan. Gut. 2012:61:507-13.

25. Fischbach W, Goebeler ME, Ruskone-Fourmestraux A, et al. Most patients with minimal histological residuals of gastric MALT lymphoma after successful eradication of helicobacter pylori can be managed safely by a watch and wait strategy: experience from a large international series. Gut. 2007:56:1685-7.

26. Chen LT, Lin JT, Tai JJ, et al. Long-term results of anti-helicobacter pylori therapy in early-stage gastric high-grade transformed MALT lymphoma. J Natl Cancer Inst. 2005;97:1345-53.

27. Sugimoto M, Kajimura M, Sato $Y$, et al. Regression of primary gastric diffuse large B-cell lymphoma after eradication of helicobacter pylori. Gastrointest Endosc. 2001:54:643-5.

28. Alsolaiman MM, Bakis $G$, Nazeer $T$, et al. Five years of complete remission of gastric diffuse large B cell lymphoma after eradication of helicobacter pylori infection. Gut. 2003;52:507-9.

29. Kuo SH, Yeh $\mathrm{KH}$, Wu MS, et al. Helicobacter pylori eradication therapy is effective in the treatment of early-stage $\mathrm{H}$ pylori-positive gastric diffuse large B-cell lymphomas. Blood. 2012;119:4838-44 quiz 5057.

30. Murata-Kamiya N, Kikuchi K, Hayashi T, et al. Helicobacter pylori exploits host membrane phosphatidylserine for delivery, localization, and pathophysiological action of the CagA oncoprotein. Cell Host Microbe. 2010;7:399-411.

31. Negrini R, Savio A, Poiesi C, et al. Antigenic mimicry between helicobacter pylori and gastric mucosa in the pathogenesis of body atrophic gastritis. Gastroenterology. 1996;111:655-65.

32. Xue LJ, Su QS, Yang JH, et al. Autoimmune responses induced by helicobacter pylori improve the prognosis of gastric carcinoma. Med Hypotheses. 2008;70:273-6.

33. Kuo SH, Chen LT, Lin CW, et al. Detection of the helicobacter pylori CagA protein in gastric mucosa-associated lymphoid tissue lymphoma cells: clinical and biological significance. Blood Cancer J. 2013;3:e125.

34. Lemma S, Karihtala P, Haapasaari KM, et al. Biological roles and prognostic values of the epithelial-mesenchymal transition-mediating transcription factors twist, ZEB1 and slug in diffuse large B-cell lymphoma. Histopathology. 2013;62:326-33.

\section{Publisher's Note}

Springer Nature remains neutral with regard to jurisdictional claims in published maps and institutional affiliations.

Ready to submit your research? Choose BMC and benefit from:

- fast, convenient online submission

- thorough peer review by experienced researchers in your field

- rapid publication on acceptance

- support for research data, including large and complex data types

- gold Open Access which fosters wider collaboration and increased citations

- maximum visibility for your research: over $100 \mathrm{M}$ website views per year

At $\mathrm{BMC}$, research is always in progress.

Learn more biomedcentral.com/submissions 